\title{
Three years of growth hormone treatment in young adults with Prader-Willi syndrome: sustained positive effects on body composition
}

Layla Damen ${ }^{1,2^{*}}$ D, Stephany H. Donze ${ }^{1,2}$, Renske J. Kuppens ${ }^{1,2}$, Nienke E. Bakker ${ }^{1,2}$, Laura C. G. de Graaff ${ }^{3}$, Janielle A. E. M. van der Velden ${ }^{4}$ and Anita C. S. Hokken-Koelega ${ }^{1,2}$

\begin{abstract}
Background: In children with Prader-Willi syndrome (PWS), the benefits of growth hormone treatment are well established. Several one-year studies have shown that growth hormone is also beneficial for adults with PWS, improving body composition. However, little is known about the longer-term effects.

This study investigated the effects on body composition in adult patients with PWS during 3 years of growth hormone therapy in a dose of $0.33 \mathrm{mg} / \mathrm{m}^{2} /$ day.
\end{abstract}

Methods: Open-label, prospective study in 43 young adults with PWS with a median (IQR) age of 19.0 (17.5 to 20.7) years. Fat mass percentage SDS and lean body mass SDS were measured annually by DXA.

Results: Estimated mean $(95 \% \mathrm{Cl})$ fat mass percentage SDS decreased during the three-year study from 2.1 (1.9 to 2.3) SDS at start to 1.9 (1.8 to 2.1) SDS, $p=0.012$, while lean body mass SDS remained stable at -2.1 ( -2.4 to -1.8$)$ SDS at start to $-1.9(-2.3$ to -1.6$)$ after 3 years, $p=0.15$. Fasting glucose and insulin remained similar during the three-year study, glucose being 4.6 (4.4 to 4.8$) \mathrm{mmol} / \mathrm{l}$ at start and 4.6 (4.5 to 4.7$) \mathrm{mmol} / \mathrm{l}$ after 3 years of growth hormone, $p=0.93$ and insulin being 59.5 (42.2 to 81.5$) \mathrm{pmol} / \mathrm{l}$ and 55.0 (42.4 to 69.2) $\mathrm{pmol} / \mathrm{l}$, resp., $p=0.54$. There were no growth hormone-related adverse events during the study.

Conclusions: Three years of growth hormone treatment in young adults with PWS maintains the positive effects on body composition attained during childhood. Thus, adults with PWS benefit from longer-term growth hormone treatment.

Trial registration: EudraCT, EudraCT number 2011-001313-14. Registered 17 October 2012.

Keywords: Prader Willi syndrome, Adults, Body composition, Growth hormone

\footnotetext{
* Correspondence: I.damen@kindengroei.nl

'Dutch Growth Research Foundation, Rotterdam, The Netherlands

${ }^{2}$ Department of Pediatrics, Subdivision of Endocrinology, Erasmus University

Medical Center-Sophia Children's Hospital, Rotterdam, the Netherlands

Full list of author information is available at the end of the article
}

(c) The Author(s). 2020 Open Access This article is licensed under a Creative Commons Attribution 4.0 International License, which permits use, sharing, adaptation, distribution and reproduction in any medium or format, as long as you give appropriate credit to the original author(s) and the source, provide a link to the Creative Commons licence, and indicate if changes were made. The images or other third party material in this article are included in the article's Creative Commons licence, unless indicated otherwise in a credit line to the material. If material is not included in the article's Creative Commons licence and your intended use is not permitted by statutory regulation or exceeds the permitted use, you will need to obtain permission directly from the copyright holder. To view a copy of this licence, visit http://creativecommons.org/licenses/by/4.0/ The Creative Commons Public Domain Dedication waiver (http://creativecommons.org/publicdomain/zero/1.0/) applies to the data made available in this article, unless otherwise stated in a credit line to the data. 


\section{Background}

Prader-Willi syndrome (PWS) is a rare genetic disorder caused by the lack of expression of the imprinted genes on the Prader-Willi region of the paternally inherited chromosome 15 . This is mostly caused by a paternal deletion or maternal uniparental disomy (mUPD) and in some cases by an imprinting center defect (ICD) or paternal chromosomal translocation [1, 2]. PWS is characterized by short stature, muscular hypotonia, developmental delay, behavioral problems and hyperphagia resulting in severe obesity when uncontrolled [2-4]. Body composition is abnormal with a high body fat percentage and a low lean body mass (LBM), even if there is no obesity [4-7]. Many of the symptoms in PWS may be explained by hypothalamic dysfunction.

In children with PWS, the benefits of growth hormone (GH) treatment are well established [5]. GH improves body composition, psychomotor development, cognition, adaptive functioning and linear growth [5, 8-11], without adverse effects on glucose parameters, lipid profile and blood pressure $[5,12]$. As a result, GH treatment has substantially changed the phenotype of children with PWS [5, 13].

Currently, when young adults with PWS without adult growth hormone deficiency (GHD) have attained adult height $(\mathrm{AH})$, they have to discontinue $\mathrm{GH}$ treatment because there is no reimbursement of $\mathrm{GH}$ for adults with PWS. However, GH studies in adults with PWS, have shown positive effects on body composition [14-19]. Our previous randomized, double-blind, placebo-controlled cross-over study (Transition Study) in 27 young adults, who were treated with $\mathrm{GH}$ during childhood and had attained adult height, showed deterioration of body composition during 1 year of placebo, while $\mathrm{GH}$ maintained the improved fat mass (FM) and LBM [14]. Other GH studies have investigated $\mathrm{GH}$ treatment for a maximum duration of 1 year [15-19]. However, these studies included patients not treated during childhood or in which treatment during childhood was not reported [15-17], consisted of small populations $[15,17,18]$ or included only patients with adult GHD [19]. Only one study reported the effects of $\mathrm{GH}$ during 2 years in adults and showed positive effects on FM and LBM [20], but, GH treatment during childhood was not reported.

We report the effects of 3 years of continuous $\mathrm{GH}$ treatment with a stable $\mathrm{GH}$ dose on body composition in adults with PWS, who were treated with GH during childhood. Given the beneficial persistent effects of long-term GH on body composition during childhood, we hypothesized that $\mathrm{GH}$ treatment in young adults with PWS would have positive effects on body composition, also on the longer-term.

\section{Methods}

\section{Patients}

For the current study, we included 43 young adults participating in the Dutch Young Adult PWS (YAP) study, coordinated by the Dutch Growth Research Foundation. Inclusion criteria were (1) genetically confirmed diagnosis of PWS by a positive methylation test, (2) $\mathrm{GH}$ treatment for at least 5 years during childhood, (3) at least 3 years of continuous GH treatment after attainment of adult height (AH), which was defined as a height velocity less than $0.5 \mathrm{~cm}$ per 6 months and a complete epiphyseal fusion. Exclusion criteria were (1) medication to reduce weight (fat), (2) non-cooperative behaviour or (3) obstructive sleep apnea syndrome.

At attainment of adult height, $\mathrm{GH}$ treatment had to be discontinued as there is no approval for $\mathrm{GH}$ treatment for adults with PWS. The YAP Study was started in 2011 to evaluate the longer-term effects and safety of $\mathrm{GH}$ treatment in young adults with PWS who were treated with GH during childhood. Patients were included either after participation in the Dutch PWS Cohort Study in children [5, 21] or the Transition Study [14].

For patients who participated in the Dutch PWS Cohort Study (the 'continuation group'), the GH dose was lowered after AH attainment from $1 \mathrm{mg} / \mathrm{m}^{2} /$ day to 0.33 $\mathrm{mg} / \mathrm{m}^{2} /$ day. Patients who participated in the Transition Study (the 'restart group'), had been without GH treatment for a median duration of 1 year before restart of $\mathrm{GH}$ in a dose of $0.33 \mathrm{mg} / \mathrm{m}^{2} /$ day. The purpose of present study was to investigate the effects of 3 years of GH with a stable dose. Therefore, we did not analyse the first year after $\mathrm{GH}$ dose lowering of patients who participated in the Cohort Study in the 3-year analyses. For the patients who participated in the Transition study, the first year after $\mathrm{GH}$ restart was not analysed either, for the sake of dose stability. We chose to exclude this first year in both groups to eliminate the influence of $\mathrm{GH}$ dose lowering or $\mathrm{GH}$ restart. However, this year was used for subanalyses of the effects of continuation of $\mathrm{GH}$ in a lower dose in the patients in the continuation group and the effects of restart of $\mathrm{GH}$ in the patients in the restart group.

In girls, hypogonadism was defined as serum oestradiol levels $<100 \mathrm{pmol} / \mathrm{L}$ and/or Tanner stage 3 or less from the age of 14 years, and/or no menarche from the age of 16 years. In boys, hypogonadism was defined as morning serum testosterone levels $<5 \mathrm{nmol} / \mathrm{L}$ and/or Tanner stage 3 or less from the age of 16 years, and/or serum testosterone levels $<10 \mathrm{nmol} / \mathrm{L}$ from the age of 18 years.

The study was approved by the Medical Ethics Committee of the Erasmus University Medical Center, Rotterdam, the Netherlands. Written informed consent 
was obtained from participants and their legal representatives.

\section{Design}

Open-label, prospective study investigating the longerterm effects of 3 years of $\mathrm{GH}$ on body composition. All participants were investigated at the Dutch PWS Reference Center in Rotterdam. Patients were treated with $\mathrm{GH}$ in a dose of $0.33 \mathrm{mg} / \mathrm{m}^{2} /$ day $(\sim 0.012 \mathrm{mg} / \mathrm{kg} /$ day $)$. The dose was adjusted based on calculated body surface area and serum IGF-I levels between 1 and 2 SDS. Patients were examined every 6 months by the PWSteam of the Dutch Growth Research Foundation in collaboration with a multidisciplinary team.

\section{Anthropometry}

Standing height was measured in centimetres with a calibrated Harpenden stadiometer. Body weight was measured in kilograms on an electric calibrated scale (Servo Balance KA-20-150S; Servo Berkel Prior, Katwijk, The Netherlands) and body mass index (BMI) was calculated. Height, weight and BMI were expressed as standard deviations scores (SDS), adjusted for age and sex according to Dutch reference values [22, 23]; BMI also according to PWS reference values [24], using GrowthAnalyser Version 4.0 (available at www.growthanalyser.org). Systolic and diastolic blood pressure were measured using an appropriately sized cuff while patients were in sitting position.

\section{Body composition}

FM and LBM were measured by DXA (Lunar Prodigy; GE Healthcare) in Erasmus MC, with daily quality assurance. The intra-assay coefficients of variation were $0.41-$ $0.88 \%$ for fat tissue and $1.57-4.49 \%$ for LBM [25]. LBM was calculated as fat-free mass minus bone mineral content. FM was also expressed as percentage of total body weight (FM\%). FM\% SDS and LBM SDS were calculated according to age- and sex-matched Dutch reference values [26].

\section{Assays}

Blood samples were collected after an overnight fast and measured in the Biochemical and Endocrine laboratories of the Erasmus Medical Center, Rotterdam. Fasting glucose and insulin were immediately assayed. Insulin levels were assessed using the Immulite 2000 assay (Siemens Healthcare Diagnostics). Interassay CV was $4.4 \%$. From 2011 to 2013, serum IGF-I and IGFBP-3 levels were assessed using the Immulite 2000 (Siemens Health-care Diagnostics, Deerfield, IL), with interassay CVs of 6.5 and $8 \%$, respectively. After 2013, IGF-I and IGFBP-3 were measured using the IDS-iSYS (Immunodiagnostic Systems), with an interassay CV of $<6.0 \%$ and $<5.1$, resp. and intra-assay $\mathrm{CV}$ of $<2.1$ and $<4.3 \%$, resp. for IGF-I and intra-assay $\mathrm{CV}<5.1 \%$ for IGFBP-3. Levels of IGF-I and IGFBP-3 were expressed as SDS, adjusting for age and gender $[27,28]$.

\section{Statistics}

Statistical analyses were performed with SPSS version 24.0 (SPSS Inc., Chicago, IL). Variables were expressed as median (interquartile range [IQR]). Changes over time were calculated using linear mixed model analysis with the outcomes measured at each time point as dependent variable with an unstructured covariance matrix. Effects are presented as estimated marginal mean (standard error of the mean, SEM or $95 \% \mathrm{CI}$ ). Differences were considered significant if the $p$-value was $<0.05$.

\section{Results}

Characteristics at start of the 3-year study

Forty-three young adults with PWS (18 males, 25 females) were included in the current study (Table 1). Median (IQR) age at start study was 19.5 (18.7 to 20.7) years for males and 18.4 (16.9 to 20.8) years for females. Adult height $(\mathrm{AH})$ was $-1.0(-1.7$ to -0.3$)$ SDS and BMI 24.5 (21.9 to 27.7$) \mathrm{kg} / \mathrm{m}^{2}$. Clinical characteristics at start of the 3-year study are shown in Table 1. Eighteen (41.9\%) patients had a deletion, $20(46.5 \%)$ an mUPD,

Table 1 Clinical characteristics at start of 3-year study

\begin{tabular}{|c|c|}
\hline & Total group \\
\hline Number (females) & $43(25)$ \\
\hline \multicolumn{2}{|l|}{ Genetic subtype } \\
\hline Deletion / mUPD / ICD / translocation & $18 / 20 / 4 / 1$ \\
\hline Age at start of childhood GH treatment (yrs) & $7.6(5.2$ to 10.1$)$ \\
\hline \multicolumn{2}{|l|}{ Age at inclusion (yrs) } \\
\hline - Males & 19.5 (18.7 to 20.7) \\
\hline - Females & 18.4 (16.9 to 20.8) \\
\hline Adult height (SDS) & $-1.0(-1.7$ to -0.3$)$ \\
\hline BMI $\left(\mathrm{kg} / \mathrm{m}^{2}\right)$ & 24.5 (21.9 to 27.7$)$ \\
\hline BMI for age (SDS) & 0.9 (0.0 to 1.8$)$ \\
\hline BMI for PWS (SDS) & $-1.4(-2.0$ to -0.7$)$ \\
\hline Fat mass percentage $(S D S)^{a}$ & $2.2(1.7$ to 2.5$)$ \\
\hline Fat mass percentage (\%) & 40.9 (34.4 to 45.6$)$ \\
\hline Lean body mass (SDS) ${ }^{a}$ & $-2.3(-2.8$ to -1.4$)$ \\
\hline GH-dose (mg/m²/day) & 0.33 (0.33 to 0.59$)$ \\
\hline GH-dose (mg/kg/day) & $0.012(0.012$ to 0.021$)$ \\
\hline IGF-I SDS ${ }^{a}$ & 1.5 (0.6 to 2.0$)$ \\
\hline
\end{tabular}

Data expressed as median (IQR)

mUPD Maternal uniparental disomy, ICD Imprinting center defect, $G H$ Growth hormone

${ }^{\mathrm{a} F M} \%$ SDS, LBM SDS and IGF-I SDS were calculated according to age- and sexmatched Dutch references [25] 
four (9.3\%) an ICD and one (2.3\%) a translocation. Thirty-three patients were on sex steroid replacement therapy (SSRT) during the study and ten were not. Not prescribing SSRT in these patients was a mutual decision between physician and caregivers based on patient characteristics at that moment (e.g. behavioural or weight problems). Seven patients were on thyroid medication.

\section{Changes during 3 years of GH treatment}

Table 2 and Fig. 1a-c show the changes in body composition and IGF-I SDS during 3 years of GH treatment in the 43 young adults. Median (IQR) GH dose during the 3-year study was 0.38 (0.33 to 0.45$) \mathrm{mg} / \mathrm{m}^{2} /$ day. Estimated mean $(95 \% \mathrm{CI})$ total body FM\% SDS decreased during 3 years of $\mathrm{GH}$ treatment from 2.1 (1.9 to 2.3) SDS at start to 1.9 (1.8 to 2.1) SDS after 3 years of GH treatment, $p=0.012$. Total body LBM SDS remained stable during 3 years of GH treatment, being $-2.1(-2.4$ to -1.8$)$ SDS at start and $-1.9(-2.3$ to -1.6$)$ SDS after 3 years, $p=0.15$. During the 3 year study, IGF-I SDS remained stable, being 1.3 (1.0 to 1.6) SDS at start and 1.2 (0.8 to 1.6) SDS after 3 years. BMI SDS and BMI PWS SDS did not change during the study.

\section{Correlations in the total group}

Neither FM\% SDS nor LBM SDS correlated with IGF-I SDS at any time point during the 3 year study. There were no significant differences in total body FM\% SDS or total body LBM SDS between the different genetic subtypes at the various time points.

\section{Safety}

Three years of continuous GH treatment was very well tolerated (Table 3). No (S)AEs considered to be GHrelated were observed. Estimated mean (95\% CI) fasting glucose and insulin remained stable during the 3-year study, glucose being 4.6 (4.4 to 4.8$) \mathrm{mmol} / \mathrm{l}$ at start and 4.6 (4.5 to 4.7 ) $\mathrm{mmol} / \mathrm{l}$ after 3 years of $\mathrm{GH}, p=0.93$, and insulin being 59.5 (42.2 to 81.5$) \mathrm{pmol} / \mathrm{l}$ at start and 55.0
(42.4 to 69.2 ) pmol $/ \mathrm{l}$ after 3 years, $p=0.54$. Systolic and diastolic blood pressure did not change significantly during 3 years of $\mathrm{GH}$. None of the patients were treated with antihypertensive medication and none of the patients developed type 2 diabetes mellitus during the study.

\section{Subanalyses of changes in the continuation group and restart group \\ Changes in the year prior to the 3-year study in patients who continued GH treatment}

The continuation group consisted of 17 patients (10 males, 7 females). In this group, the median (IQR) age at GH dose lowering after $\mathrm{AH}$ was 17.7 (17.1 to 18.4) years for males and 15.9 (14.8 to 17.4) years for females. Adult height $(\mathrm{AH})$ was $-0.4(-1.7$ to -0.2$)$ SDS and BMI 22.0 (19.7 to 25.4$) \mathrm{kg} / \mathrm{m}^{2}$, being 0.6 (-0.1 to 1.5$)$ SDS. Six (35.3\%) patients had a deletion, nine (52.9\%) an mUPD and two $(11.8 \%)$ an ICD.

Figure 2a-c shows the changes in median $\mathrm{GH}$ dose and body composition and IGF-I SDS, in estimated marginal means, during $\mathrm{GH}$ treatment in the 17 patients who continued $\mathrm{GH}$ after $\mathrm{AH}$ attainment. All subjects were treated with $\mathrm{GH}$ during childhood, with a median (IQR) GH dose at $\mathrm{AH}$ attainment of 1.0 (0.67 to 1.0) $\mathrm{mg} / \mathrm{m}^{2} /$ day and estimated mean $(95 \% \mathrm{CI})$ IGF-I SDS was 2.4 (1.6 to 3.2) SDS. After AH attainment, the GH dose was reduced to $0.33 \mathrm{mg} / \mathrm{m}^{2} /$ day and in case of IGF-I SDS levels below or above our target of 1 to 2 SDS, the $\mathrm{GH}$ dose was adjusted. After 1 year, estimated mean (95\% CI) IGF-I SDS was 1.5 (1.0 to 2.0) SDS, which was significantly lower than the 2.4 (1.6 to 3.2) SDS at AH attainment, $p=0.014$. Following dose lowering, estimated mean (95\% CI) total body FM\% SDS increased significantly from 2.2 (1.9 to 2.4) SDS at AH attainment to 2.3 (2.1 to 2.5) SDS at 6 months after dose lowering, $p=0.009$. The next 6 months of treatment FM\% SDS remained stable. Estimated mean $(95 \% \mathrm{CI})$ total body

Table 2 Body composition during the 3-year study

\begin{tabular}{|c|c|c|c|c|c|}
\hline & At start & After 1 year & After 2 years & After 3 years & $P$-value* \\
\hline \multicolumn{6}{|l|}{ Total group } \\
\hline Total body FM\% (SDS) & 2.1 (1.9 to 2.3 ) & 2.0 (1.9 to 2.2 ) & 2.0 (1.8 to 2.1$)$ & 1.9 (1.8 to 2.1$)$ & 0.012 \\
\hline Total body FM\% & 39.6 (36.7 to 42.6) & 39.4 (36.7 to 42.1$)$ & 39.0 (36.4 to 41.6$)$ & 38.9 (36.2 to 41.6) & 0.37 \\
\hline Total body LBM (SDS) & $-2.1(-2.4$ to -1.8$)$ & $-2.0(-2.3$ to -1.7$)$ & $-1.9(-2.3$ to -1.6$)$ & $-1.9(-2.3$ to -1.6$)$ & 0.15 \\
\hline Total body LBM (kg) & 39.8 (37.4 to 42.2) & 40.7 (38.4 to 43.0$)$ & 41.2 (38.8 to 43.5$)$ & 40.7 (38.4 to 43.0) & 0.17 \\
\hline BMI SDS & 0.9 (0.5 to 1.3$)$ & $0.9(0.5$ to 1.3$)$ & 0.9 (0.5 to 1.3$)$ & 0.9 (0.5 to 1.2$)$ & 0.60 \\
\hline BMI PWS SDS & $-1.6(-1.9$ to -1.2$)$ & $-1.6(-2.0$ to -1.2$)$ & $-1.7(-2.0$ to -1.3$)$ & $-1.7(-2.1$ to -1.3$)$ & 0.08 \\
\hline IGF-I SDS & 1.3 (1.0 to 1.6$)$ & 1.5 (1.1 to 1.9$)$ & 1.2 (0.8 to 1.6$)$ & 1.2 (0.8 to 1.6$)$ & 0.49 \\
\hline
\end{tabular}

Data are expressed as estimated means (95\% CI). FM SDS, FM\% SDS and LBM SDS were calculated according to age- and sex-matched Dutch references [25] * $P$-value of the change during 3 years of $\mathrm{GH}$ treatment 


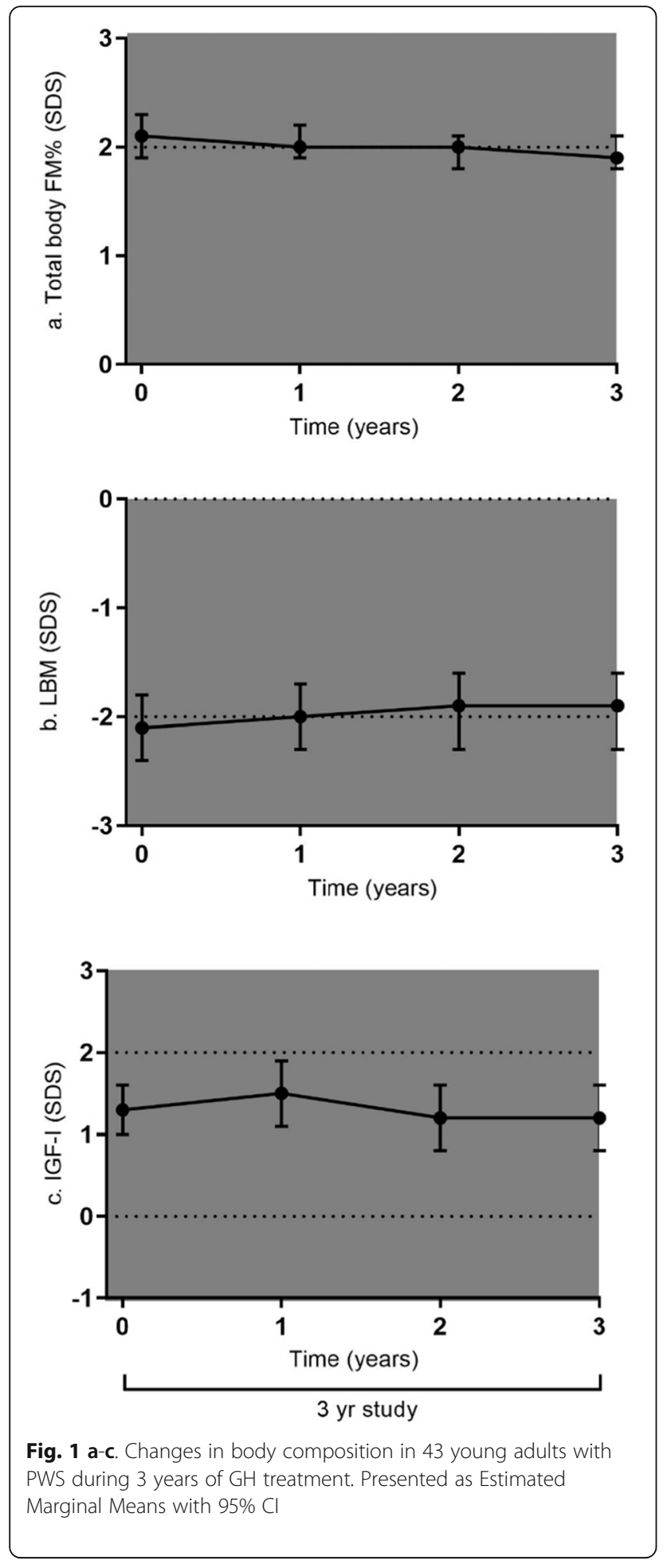

LBM SDS decreased following dose lowering from -2.2 $(-2.8$ to -1.6$)$ SDS to $-2.3(-2.8$ to -1.8$)$ SDS after 6 months, but this decrease was not significant $(p=0.26)$. The next 6 months of treatment LBM SDS remained stable.

\section{Changes in the year prior to the 3-year study in patients who restarted GH treatment}

The restart group consisted of 26 patients ( 8 males, 18 females), of which 21 had participated in the Transition study [14]. Median (IQR) duration of cessation of GH treatment was 1 (1 to 1 ) year. In this group, median (IQR) age at GH restart was 19.8 (19.2 to 21.1) years for males and 19.1 (16.2 to 20.1) years for females, and adult height was - 1.1 ( -1.8 to -0.7$)$ SDS and BMI 24.8 (20.3 to 28.9$) \mathrm{kg} / \mathrm{m}^{2}$, being $1.2(-0.5$ to 2.2$)$ SDS. Twelve (46.1\%) had a deletion, 11 (42.3\%) an mUPD, two (7.6\%) an ICD and one (3.8\%) a translocation.

Figure $2 \mathrm{~d}$-f shows the changes in median GH dose and estimated marginal mean body composition and IGF-I SDS in the 26 patients who restarted GH. At restart, after cessation of GH treatment for a median duration of 1 year, estimated mean $(95 \% \mathrm{CI})$ IGF-I SDS was $-0.4(-0.7$ to $0.0)$ SDS. GH treatment was restarted in a median (IQR) dose of 0.33 (0.33 to 0.35$) \mathrm{mg} / \mathrm{m}^{2} /$ day. After 1 year, IGF-I SDS was 1.2 (0.8 to 1.7) SDS, which was significantly higher than at restart, $p<0.001$. Estimated mean $(95 \% \mathrm{CI})$ FM\% SDS after 1 year without GH was 2.2 (2.0 to 2.4) SDS, during the first 6 months of $\mathrm{GH}$, there was a significant decrease in FM\% SDS to 2.1 (1.9 to 2.3) SDS, $p=0.03$, which decreased further during the next 6 months to 2.0 (1.7 to 2.2) SDS, $p=0.02$. LBM SDS at restart of GH was $-2.3(-2.7$ to -2.0$)$ SDS. During the first 6 months of GH there was a significant increase of LBM SDS to $-2.0(-2.5$ to -1.6$)$ SDS, $p=0.008$, which remained stable during the next 6 months of GH (-2.0 (-2.4 to -1.6$)$ SDS).

\section{Discussion}

To our knowledge, this is the first prospective study to describe the effects of 3 years of continuous GH treatment with a stable GH dose in young adults with PWS who were treated with $\mathrm{GH}$ for several years during childhood. Our findings demonstrate that GH treatment in young adults with PWS has sustained positive effects on body composition, maintaining the improved FM\% SDS and LBM SDS attained during childhood. We did not find any GH-related adverse events.

Long-term GH treatment during childhood has wellknown beneficial effects on body composition [5]. Present study describes the beneficial effects of 3 years of GH treatment in young adults with PWS who were treated with GH for several years during childhood. We found that longer-term GH treatment keeps FM\% SDS and LBM SDS stable. These results are in line with our previous study regarding the effects of $\mathrm{GH}$ treatment in children with PWS, in which longer-term GH treatment had also sustained positive effects and led to a stable body composition [5]. 
Table 3 Safety parameters in total group during the 3-yar study

\begin{tabular}{llllll}
\hline & At start & After 1 year & After 2 years & After 3 years & $P$-value* \\
\hline Fasting glucose $(\mathrm{mmol} / \mathrm{l})$ & $4.6(4.4$ to 4.8$)$ & $4.7(4.5$ to 4.9$)$ & $4.8(4.6$ to 4.9$)$ & $4.6(4.5$ to 4.7$)$ & 0.93 \\
Fasting insulin $(\mathrm{pmol} / \mathrm{l})$ & $59.5(45.2$ to 81.5$)$ & $67.6(55.0$ to 81.5$)$ & $64.5(51.6$ to 78.7$)$ & $55.0(42.4$ to 69.2$)$ & 0.54 \\
Systolic BP $(\mathrm{mmHg})^{*}$ & $120.2(116.5$ to 123.9$)$ & $123.9(120.6$ to 127.1$)$ & $122.7(118.6$ to 126.8$)$ & $121.4(116.4$ to 126.3$)$ & 0.68 \\
Diastolic BP $(\mathrm{mmHg})^{*}$ & $73.1(70.5$ to 75.7$)$ & $73.0(71.1$ to 75.0$)$ & $74.3(72.0$ to 76.5$)$ & $73.6(70.9$ to 76.3$)$ & 0.78 \\
\hline
\end{tabular}

Data are expressed as estimated means $(95 \% \mathrm{Cl}) . \mathrm{BP}$ Blood pressure. * corrected for sex and height

${ }^{*} P$-value of the change during 3 years of $\mathrm{GH}$ treatment

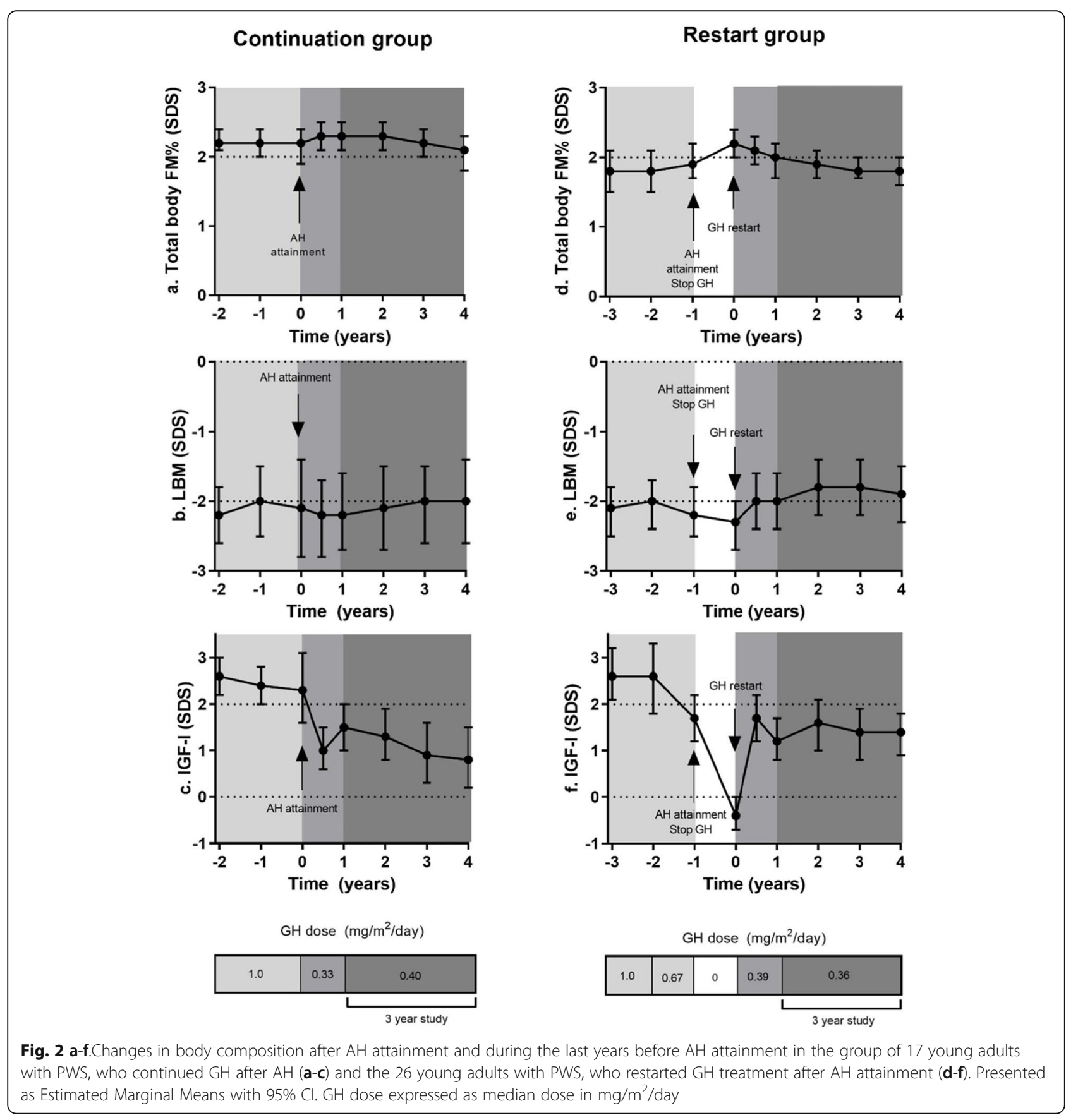


We did not find any changes in BMI SDS during 3 years of GH treatment, which is in agreement with the 1 year studies [16-20]. We emphasize that measurement of body composition in patients with PWS is much more informative than BMI, since BMI was within normal ranges for most patients throughout our study, while body composition was abnormal. BMI is, therefore, not an appropriate parameter in PWS.

Blood pressure did not significantly change during the 3 -year study and we did not find any GH-related adverse events. Fasting glucose and insulin levels remained stable. This suggests that the GH dose used in our study is also safe on the longer-term term. However, very long-term data are required to find which $\mathrm{GH}$ dose is optimal for a most favorable effect on body composition with the lowest possible risk for adverse events.

In patients who restarted $\mathrm{GH}$, after discontinuation for a median duration of 1 year, we found a decrease of FM\% SDS and an increase in LBM SDS during the first year of $\mathrm{GH}$ treatment compared to measurements after 1 year of $\mathrm{GH}$ discontinuation. Therefore, restart of GH is able to recover the positive effects on body composition after a deterioration during 1 year of GH discontinuation.

Other studies investigating 1 year of GH treatment also showed positive effects on body composition [15-19]. A study by Butler et al., in 11 GH-naive adults with PWS, found an improvement of body composition during 1 year of GH treatment. In that study, 1 year of GH treatment was followed by 1 year observational period without $\mathrm{GH}$ treatment. After that year, the young adults had regained more fat mass than they lost during 1 year GH treatment [17]. Our previous randomized, double-blind, placebocontrolled, cross-over trial, also showed a deterioration of FM during 1 year of placebo, while 1 year of GH maintained the improved body composition attained during childhood [14]. Our present study demonstrates that GH treatment for longer time maintains the improved body composition in young adults with PWS.

Only one study by Sode-Carlsen et al. investigated the effects of 2 years of $\mathrm{GH}$ treatment in 39 young adults with PWS, but GH treatment during childhood was not recorded [20]. They report an increase in LBM of $2.8 \mathrm{~kg}$ after 2 years of $\mathrm{GH}$, which is in line with our study. Unfortunately, the change in FM\% was not reported in the study, but they describe a decrease in total FM of $3.0 \mathrm{~kg}$ after 2 years of GH. As in our study, they reported no serious or unexpected adverse events [20].

In the patients who continued $\mathrm{GH}$, we found an increase in FM\% SDS during the first 6 months after AH attainment in the group who immediately continued $\mathrm{GH}$ after $\mathrm{AH}$ attainment. An explanation for this increase could be that, after $\mathrm{AH}$ attainment, the $\mathrm{GH}$ dose was lowered from $1 \mathrm{mg} / \mathrm{m}^{2} /$ day to $0.33 \mathrm{mg} / \mathrm{m}^{2} /$ day. This suggests that $\mathrm{GH}$ stop, restart or dose lowering is followed by a change in body composition.

Since the young adults in our study had attained adult height, we did not want to continue the childhood dose of $1.0 \mathrm{mg} / \mathrm{m}^{2} /$ day. We, therefore, chose a starting dose of $0.33 \mathrm{mg} / \mathrm{m}^{2} /$ day after $\mathrm{AH}$ attainment and we titrated the GH dose to IGF-I levels between 1 and 2 SDS. During the 3-year study the median dose was $0.38 \mathrm{mg} / \mathrm{m}^{2} /$ day, which corresponded to a median daily dose of $0.70 \mathrm{mg}$, which is in line with other studies in young adults $[15,16,18-20]$. In order to investigate the effects of a stable dosage of $\mathrm{GH}$ in the total group, we decided to only use measurements after 1 year of $\mathrm{GH}$ in a dose of $0.33 \mathrm{mg} /$ $\mathrm{m}^{2} /$ day as starting point for the 3-year study. At that moment, IGF-I SDS was 1.3 (1.0 to 1.6) SDS at a median daily GH dose of $0.70 \mathrm{mg}$. GH dose and IGF-I SDS values remained stable during the 3-year study, which allowed us to investigate the effects of 3 years of GH treatment with a stable GH dose. The Growth Hormone Research Society Workshop published a consensus guideline for $\mathrm{GH}$ treatment in PWS and suggested that a serum IGF-I level of 0 to 2 SDS would be optimal [29]. During our 3-year study, IGFI levels remained within these ranges.

Our study did not include a control group of PWS patients who did not receive GH treatment. Since our previous GH-placebo study showed a deterioration of body composition during 1 year of placebo [14], it was considered unethical to withhold GH treatment for a longer period in these young adults. Studies in adults not treated with GH reported FM percentages of at least $50 \%[17,18,30]$, while in our present study the estimated mean FM\% at the end of the 3-year study was $38.9 \%$.

\section{Conclusion}

In conclusion, our 3-year study in 43 young adults with PWS who were treated with GH during childhood shows that GH treatment maintains the improved body composition attained during childhood. Furthermore, it shows that restart of GH after 1 year of discontinuation is able to restore the deteriorated body composition with a decrease in FM\% SDS and LBM SDS during the first year and sustained effects thereafter. No major side effects or safety concerns were seen. Based on our findings, we conclude that adult patients with PWS benefit from GH treatment.

\section{Acknowledgments}

We express our gratitude to all children and parents for their enthusiastic participation in this study and thank Mariëlle van Eekelen, Laura Schafthuizen and Ezra Piso, research nurses, for all their work. We thank all collaborating pediatric-endocrinologists, pediatricians and other health care providers. 


\section{Authors' contributions}

LD: Substantial contribution to acquisition of data, analysis and interpretation of data and drafting the manuscript. SHD: Substantial contribution to acquisition of data, interpretation of data and critical revision of the manuscript. RJK: Substantial contribution to acquisition of data, interpretation of data and critical revision of the manuscript. NEB: Substantial contribution to acquisition of data, interpretation of data and critical revision of the manuscript. LCdG: Substantial contribution to interpretation of data and critical revision of the manuscript. JAvA: Substantial contribution to interpretation of data and critical revision of the manuscript. AHK: Substantial contribution of conception and design of study, analysis and interpretation of data and critical revisions of the manuscript. All authors read and approved the final manuscript.

\section{Funding}

This study was an investigator-initiated study, supported by an independent research grant from Pfizer. Pfizer was neither involved in conception or design of the study, nor in collection, analysis or interpretation of data, writing the manuscript, or decision to submit the manuscript for publication.

\section{Availability of data and materials}

The datasets generated and/or analysed during the current study are not publicly available due to privacy and ethical restrictions but are available from the corresponding author on reasonable request.

\section{Ethics approval and consent to participate}

Written informed consent was obtained from patients and parents. The study protocol was approved by the Medical Ethics Committee of the Erasmus University Medical Center, Rotterdam.

\section{Consent for publication}

Not applicable.

\section{Competing interests}

Investigator-initiated study for which AHK received an independent research grant from Pfizer. The other authors declared no conflict of interest exists.

\section{Author details}

'Dutch Growth Research Foundation, Rotterdam, The Netherlands. ${ }^{2}$ Department of Pediatrics, Subdivision of Endocrinology, Erasmus University Medical Center-Sophia Children's Hospital, Rotterdam, the Netherlands. ${ }^{3}$ Internal Medicine, Division of Endocrinology, Erasmus University Medical Center, Rotterdam, the Netherlands. ${ }^{4}$ Department of Pediatrics, Subdivision of Endocrinology, Radboud University Medical Center-Amalia Children's Hospital, Nijmegen, The Netherlands.

Received: 26 February 2020 Accepted: 15 June 2020

Published online: 24 June 2020

\section{References}

1. Cassidy SB, Driscoll DJ. Prader-Willi syndrome. Eur J Hum Genet. 2009;17(1):3-13.

2. Goldstone AP, Holland AJ, Hauffa BP, Hokken-Koelega AC, Tauber M Recommendations for the diagnosis and management of Prader-Willi syndrome. J Clin Endocrinol Metab. 2008;93(11):4183-97.

3. Holm VA, Cassidy SB, Butler MG, Hanchett JM, Greenswag LR, Whitman BY, et al. Prader-Willi syndrome: consensus diagnostic criteria. Pediatrics. 1993; 91(2):398-402.

4. Cassidy SB. Prader-Willi syndrome. J Med Genet. 1997;34(11):917-23.

5. Bakker NE, Kuppens RJ, Siemensma EP, Tummers-de Lind van Wijngaarden RF, Festen DA, Bindels-de Heus GC, et al. Eight years of growth hormone treatment in children with Prader-Willi syndrome: maintaining the positive effects. J Clin Endocrinol Metab. 2013;98(10):4013-22.

6. Bekx MT, Carrel AL, Shriver TC, Li Z, Allen DB. Decreased energy expenditure is caused by abnormal body composition in infants with Prader-Willi syndrome. J Pediatr. 2003;143(3):372-6.

7. Brambilla P, Bosio L, Manzoni P, Pietrobelli A, Beccaria L, Chiumello G. Peculiar body composition in patients with Prader-Labhart-Willi syndrome. Am J Clin Nutr. 1997;65(5):1369-74.

8. Festen DA, Wevers M, Lindgren AC, Bohm B, Otten BJ, Wit JM, et al. Mental and motor development before and during growth hormone treatment in infants and toddlers with Prader-Willi syndrome. Clin Endocrinol. 2008;68(6): 919-25.

9. Siemensma EP, Tummers-de Lind van Wijngaarden RF, Festen DA, Troeman ZC, van Alfen-van der Velden AA, Otten BJ, et al. Beneficial effects of growth hormone treatment on cognition in children with Prader-Willi syndrome: a randomized controlled trial and longitudinal study. J Clin Endocrinol Metab. 2012;97(7):2307-14.

10. Lo ST, Siemensma E, Collin P, Hokken-Koelega A. Impaired theory of mind and symptoms of autism spectrum disorder in children with Prader-Willi syndrome. Res Dev Disabil. 2013;34(9):2764-73.

11. Lo ST, Festen DA, Tummers-de Lind van Wijngaarden RF, Collin PJ, HokkenKoelega AC. Beneficial effects of long-term growth hormone treatment on adaptive functioning in infants with Prader-Willi syndrome. Am J Intellect Dev Disabil. 2015;120(4):315-27.

12. Coupaye M, Lorenzini F, Lloret-Linares C, Molinas C, Pinto G, Diene G, et al. Growth hormone therapy for children and adolescents with Prader-Willi syndrome is associated with improved body composition and metabolic status in adulthood. J Clin Endocrinol Metab. 2013;98(2):E328-35.

13. Carrel AL, Myers SE, Whitman BY, Eickhoff J, Allen DB. Long-term growth hormone therapy changes the natural history of body composition and motor function in children with prader-willi syndrome. J Clin Endocrinol Metab. 2010;95(3):1131-6.

14. Kuppens RJ, Bakker NE, Siemensma EP, Tummers-de Lind van Wijngaarden $\mathrm{RF}$, Donze SH, Festen DA, et al. Beneficial effects of $\mathrm{GH}$ in young adults with Prader-Willi syndrome: a 2-year crossover trial. J Clin Endocrinol Metab. 2016;101(11):4110-6.

15. Hoybye C, Hilding A, Jacobsson H, Thoren M. Growth hormone treatment improves body composition in adults with Prader-Willi syndrome. Clin Endocrinol. 2003;58(5):653-61.

16. Sode-Carlsen R, Farholt S, Rabben KF, Bollerslev J, Schreiner T, Jurik AG, et al. One year of growth hormone treatment in adults with Prader-Willi syndrome improves body composition: results from a randomized, placebocontrolled study. J Clin Endocrinol Metab. 2010;95(11):4943-50.

17. Butler MG, Smith BK, Lee J, Gibson C, Schmoll C, Moore WV, et al. Effects of growth hormone treatment in adults with Prader-Willi syndrome. Growth Hormon IGF Res. 2013:23(3):81-7.

18. Gondoni LA, Vismara L, Marzullo P, Vettor R, Liuzzi A, Grugni G. Growth hormone therapy improves exercise capacity in adult patients with PraderWilli syndrome. J Endocrinol Investig. 2008;31(9):765-72.

19. Mogul HR, Lee PD, Whitman BY, Zipf WB, Frey M, Myers S, et al. Growth hormone treatment of adults with Prader-Willi syndrome and growth hormone deficiency improves lean body mass, fractional body fat, and serum triiodothyronine without glucose impairment: results from the United States multicenter trial. J Clin Endocrinol Metab. 2008;93(4):1238-45.

20. Sode-Carlsen R, Farholt S, Rabben KF, Bollerslev J, Schreiner T, Jurik AG, et al. Growth hormone treatment for two years is safe and effective in adults with Prader-Willi syndrome. Growth Hormon IGF Res. 2011;21(4):185-90.

21. de Lind van Wijngaarden RF, Siemensma EP, Festen DA, Otten BJ, van Mil EG, Rotteveel J, et al. Efficacy and safety of long-term continuous growth hormone treatment in children with Prader-Willi syndrome. J Clin Endocrinol Metab. 2009.94(11):4205-15.

22. Fredriks AM, van Buuren S, Burgmeijer RJ, Meulmeester JF, Beuker RJ, Brugman $E$, et al. Continuing positive secular growth change in the Netherlands 1955-1997. Pediatr Res. 2000;47(3):316-23.

23. Fredriks AM, van Buuren S, Wit JM, Verloove-Vanhorick SP. Body index measurements in 1996-7 compared with 1980. Arch Dis Child. 2000;82(2):107-12.

24. Hauffa BP, Schlippe G, Roos M, Gillessen-Kaesbach G, Gasser T. Spontaneous growth in German children and adolescents with genetically confirmed Prader-Willi syndrome. Acta Paediatr. 2000;89(11):1302-11.

25. Guo Y, Franks PW, Brookshire T, Antonio Tataranni P. The intra- and interinstrument reliability of DXA based on ex vivo soft tissue measurements. Obes Res. 2004;12(12):1925-9.

26. Boot AM, Bouquet J, de Ridder MA, Krenning EP, de Muinck Keizer-Schrama SM. Determinants of body composition measured by dual-energy X-ray absorptiometry in Dutch children and adolescents. Am J Clin Nutr. 1997; 66(2):232-8.

27. Bidlingmaier M, Friedrich N, Emeny RT, Spranger J, Wolthers OD, Roswall J, et al. Reference intervals for insulin-like growth factor-1 (igf-i) from birth to senescence: results from a multicenter study using a new automated chemiluminescence IGF-I immunoassay conforming to recent international recommendations. J Clin Endocrinol Metab. 2014;99(5):1712-21. 
28. Rikken B, van Doorn J, Ringeling A, Van den Brande JL, Massa G, Wit JM. Plasma levels of insulin-like growth factor (IGF)-I, IGF-II and IGF-binding protein-3 in the evaluation of childhood growth hormone deficiency. Horm Res. 1998;50(3):166-76.

29. Deal CL, Tony M, Hoybye C, Allen DB, Tauber M, Christiansen JS, et al. GrowthHormone Research Society workshop summary: consensus guidelines for recombinant human growth hormone therapy in Prader-Willi syndrome. J Clin Endocrinol Metab. 2013;98(6):E1072-87.

30. Theodoro MF, Talebizadeh Z, Butler MG. Body composition and fatness patterns in Prader-Willi syndrome: comparison with simple obesity. Obesity (Silver Spring). 2006;14(10):1685-90.

\section{Publisher's Note}

Springer Nature remains neutral with regard to jurisdictional claims in published maps and institutional affiliations.

Ready to submit your research? Choose BMC and benefit from:

- fast, convenient online submission

- thorough peer review by experienced researchers in your field

- rapid publication on acceptance

- support for research data, including large and complex data types

- gold Open Access which fosters wider collaboration and increased citations

- maximum visibility for your research: over $100 \mathrm{M}$ website views per year

At BMC, research is always in progress.

Learn more biomedcentral.com/submissions 